\title{
City Image Analysis of Food in Guangzhou - Taking Yamaha Fish Stall as an Example
}

\author{
Zihua Zhan, Runting Li ${ }^{*}$ \\ School of Communication and Media, Guangzhou Huashang College, Guangzhou 511300, Guangdong Province, China
}

*Corresponding author: Runting Li, xxxyc123456@163.com

\begin{abstract}
In the representation system of city image, food has become a huge influence in the process of city image construction. In the construction of "food as the sky" as the city image of Guangzhou, it includes three forms: prototype image, conceptual image, and symbol image. There are several differences in the three forms, and the myth of "eating in Guangzhou" is constructed in the specific visual practice.
\end{abstract}

Keywords: Food in Guangzhou; City image; Yamaha Fish Stall

Publication date: December 2021; Online publication: December 31, 2021

\section{Introduction}

United Nations (UN) experts predict that the world urbanization rate will reach $60 \%$ by 2030 , and the rapid rise of cities in China's political, economic, and cultural system has been the most important part of China's evolution in the past four decades. There are many studies on city image, and most of the horizons are limited to "city planning," "city marketing," "city branding," and "tourism promotion." In Semiology and Urbanism, Roland Barthes pointed out that "city" is ultimately just a word, indicating that a city is not just a material space but has certain humanistic characteristics.

The Modern Chinese Dictionary defines city as a place where there is a concentrated non-agricultural population with developed industry and commerce, and it is usually the political, economic, and cultural center of the surrounding areas. According to psychologists, image is a psychological concept that refers to the overall impression of something formed in the brain through various sensory organs; that is, a perception through the reproduction of various senses. Therefore, city image can be defined as an intangible asset of a city, referring to the overall impression of the city in the minds of the public ${ }^{[1]}$. Since the image plays a media function in the epistemological sense, how does this perception form? That is, how can the "image" be formed? In fact, "image" is not a complete psychological activity, but it requires a material basis.

The shape of all things does not have any significance and value without entering people's perceptual thinking. In order to analyze and grasp the image of the city, the most common research idea is to enter the established visual text world. The film, Yamaha Fish Stall is full of Guangzhou's rich life atmosphere, with a unique fragrance of the south and has become a very good visual text.

\section{Literature review}

On September 11, 2018, the White Paper on Short Video and Urban Image Research released a set of methodological law for urban image video shooting - BEST, which stands for BGM (urban music), Eating (local diet), Scenery (landscape scenery), and Technology (technological facilities) ${ }^{[2]}$. Media plays a great influence in the formation of city image, and this influence is becoming more and more significant along with the development of new media technology and its embedding in daily life. Since the image plays a 
media function in the epistemological sense, how does this perception form? That is, how can the "images" be formed? In fact, "image" is not a complete psychological activity but requires a material basis. Based on the material perspective of the city, the city plays a role as a spatial medium. It connects intuitive locations and representation symbols as well as provides a place for a specific survival form. In Yamaha Fish Stall, the response is a process of city image processing; it is not negative, and there are various cultural ideas in the city seen in the construction, streets, restaurants, and fish stalls throughout daily life and material activities. In the description of Guangzhou amorous feelings, the feelings, faith, and memory provide people a sense of "existence" to gather. The space, imagery, and symbols in the film do not exist in isolation, rather they help one to understand the city and everyone in the city ${ }^{[3]}$.

In early 1985, Yamaha Fish Stall went abroad at the 35th Berlin Film Festival. In the same year, the film was awarded the second prize in the Best Film Awards by the Ministry of Culture.

\section{Three forms of city image and their production principles}

In the representation of urban discourse, the combination of material and spirit means that material enters the network of meaning. Yamaha Fish Stall is known as the "contemporary Guangzhou Qingming Festival Riverside Scene" because the people and things depicted in the film have the potential of performance and representation. They are not empirical images, but through the simple and abstract processing of visual thinking activities, they become a pure form in the field of consciousness. Once this form enters the field of consciousness and accepts the engraving and processing of subjective consciousness, it becomes an image in the sense of visual perception ${ }^{[4]}$.

\subsection{Prototype image and the image production of marine culture}

Like any symbol and its reference system, the image accepts the carving of history, culture, and subject consciousness, and finally presents a state of flow in the long river of time. However, compared with other imagery forms, the prototype is a cultural construct, reflecting a generally shared mode of understanding, and thus having the greatest stability ${ }^{[4]}$. This is because the archetypes rooted in the collective unconscious domain imply a congenital system of meaning. Chinese marine culture has a long history. Tao Siyan once stressed in his book, Chinese Marine Culture, that in the age of the top of the mountain, fish has shown a cultural function in the society; it does not only serve as a reliable source of food for human beings but also constitute a mysterious image of the spiritual world ${ }^{[5]}$. In the Economic and Philosophic Manuscripts, Marx said, "Mankind's persistent intention of survival and development makes marine culture clear and utilitarian. On the one hand, fish is a source of food and a first-hand source of production and life; on the other hand, it brings sensory humanity as a conceptual image and humanized nature ${ }^{[6]}$." For example, the activities of fishing has long been a relatively popular leisure way in people's life. In various traditional folk-art forms, such as New Year pictures, paper cutting, embroidery, kites, and so on, fish is still one of the active modeling elements. The artistic image of fish has therefore become one of the symbols with auspicious meaning and one that visually reflects the traditional Chinese culture. Yamaha Fish Stall uses images of fishermen's unique life, customs, religious beliefs, and other contents. The hometown of fish and rice, the love for fish and water, diving, and so on condense the unremitting pursuit and expectation of ordinary people from generation to generation, containing rich cultural values.

Marine culture contains the spirit of pioneering marine culture despite difficulties and dangers. Yamaha Fish Stall was the first to reflect the citizens life in Guangzhou after the reform and opening-up. In 1984, people still had doubts about commodity economy, but the film tore the corner of the planned economy to being "employed" as the leading role, made the city open and fresh at the forefront of reform, wrote a new chapter of Lingnan culture in the history of Chinese films, and combined the city with the spirit just like a 
sea with a wide vision. When fishermen face the sea, fishermen have a desire to survive and summon up the courage to surpass the sea; just like people running around through hardships, ups and downs, and into one dilemma after another, but indomitably going through them to open up their own way to life. They always compete with a complex world that develops unexpectedly, with opportunities and dangers coexisting, but always invincible. In front of the two fundamental and eternal themes of human survival and development, the people in Guangzhou are very wise to clarify the relationship between each other and correct each other. Therefore, the continuous enterprising spirit of common development and innovation contains the wisdom of life. Yamaha Fish Stall carries the regional image of marine culture daring to lead the world, and it has what Marx calls the perceived charm of human nature.

\subsection{Concept image and Guangzhou city image diversity}

Yamaha Fish Stall is the first time that its individual economy is shown on the big screen. In 1984, the film was rehearsed at Peking University. With tears after watching the film, people could hardly believe that young people who sold fishes could become "10,000-yuan households," standing up and shouting, "Guangdong today is our tomorrow." As Mitchell once said, "A notable mark of the 'image turn' is that it forms specific social and cultural constructs with the help of rhetoric. The boundaries of other cultures opened by vision are the boundaries of society. Whatever the visual culture is, it is necessarily rooted in the construction of subjectivity, identity, desire, memory, and imagination ${ }^{[7]}$." In the crowded modern city, vitality is boiling in search of an erupting crater. "Street boys, street girls" - this is not what a great personality ideal is, or even the problem of the youth, but it was several unemployed young people in the 1980s who realized their self-value and created a better life. At that time, there were more than 600,000 self-employed people engaging in various snack bars, repair shops, and clothing stores in Guangzhou. A prominent problem in any society is how ordinary citizens "live like individuals" and how to maintain dignity and prosper. "Street boys, street girls" is full of setbacks but a happy entrepreneurial history provides a model. With personality, it began to speak to the public. The ordinary image aroused a warm response among the audience. Objectively speaking, "street boys, street girls" is a new concept born under specific historical conditions - the reform in the 1980s, thereby being a part of the reform. In essence, urban culture involves the mutual relationship between "city" and "people," just as "city is the people, and only where people are found, there will be a city." The emergence of "street boys, street girls" in Guangzhou city itself is a metaphor, in order to correct the name of money-making and to give the public an understanding to grasp real life from the concept framework of openness.

\subsection{Symbol imagery and symbols of a better life}

When a symbol form obtains a universal social recognition foundation and carries a certain amount of recognition discourse, it becomes a symbol image ${ }^{[4]}$. The bustling Longzhu Market, Fangcun Fresh Water Fish Bar, the noisy Chengzhu Teahouse, Xiguan Dawu, stone street, octopus footbridge, etc. in the film leads today's audience to Guangzhou 40 years ago, experiencing the vitality and atmosphere of Yangcheng under the spring breeze of reform. The reason why Longzhu Market, Chengzhu Teahouse, Xiguan Dawu, Shajichong, and so on have evolved into typical images carrying emotions is precisely because of the repeated acquisition and recruitment of people from different times, thus forming a huge intertext network, which has become a "symbol" through cultural precipitation. Since the Ming and Qing Dynasties, Guangzhou was a Trade Port. At that time, Xiguan area was rich and economical. Today, Baohua Road, Duobao Road, and Fengyuan Square in Liwan District have gathered. Guangzhou people are always lowkey and pragmatic because they have seen the world. The people in Guangzhou have strong confidence in culture for more than 100 years, and they have high acceptance for foreign culture. While accepting it, they 
would also screen and learn it.

Chengzi Teahouse, Xiguan Dawu, and Shajichong have important significance. They connect to the past and carry on the past. Several important plays of the film have been performed in these scenes in the context of "food." The story of "food is the day for the people" is sacred yet vulgar, familiar yet strange, and ordinary yet bizarre. Yu Dewu is in-charged of self-employed license and is greedy, whereas the waitress in Shajichong is warm and thoughtful. This is just like the mixture of taste in food. Boat porridge, roast pork, white-cut chicken, roast goose, suckling pig - whether tasteful or tasteless, life image is forever. The living world designated by the city for its residents, and the meaning of existence that people are endowed with are the positive expressions of "food in Guangzhou."

\section{Conclusion}

City image covers a variety of contents, such as roads, buildings, food culture, living culture, and so on. This paper focuses on the construction of food culture in the city image. Marine culture is the prototype image of Guangzhou city, symbolizing the sea, where rivers are embraced by the people of Guangzhou, and they are always leading the tide. It is under the open spirit of the reform that "street girls" have attained a lucky way to "live like individuals." Chengzhu Teahouse, Longzhu Market, Shajichong, and so on carry the memory of the people. Fish balls, goose burning, and boat porridge are all symbols of life. Prototype image, concept image, and symbol image are unified in the framework of Guangzhou. In fact, occupation in modern society is not only for an individual to make a living, but also means of social recognition, dignity, and value. Xiguan Dawu, Longzhu Market, and others also created a set of Guangzhou memories, using material social settings, constituting an expanding social space, and jointly producing "Guangzhou" in the historical and cultural context. Therefore, in the process of constructing the city image of Guangzhou, the daily life image of the local people is embedded in the unique text, showing the image of the city with a strong life atmosphere. Driven by emotional elements, the city image of Guangzhou is constructed with a sense of level and temperature. Especially today, new media and big data technologies have infiltrated into various processes of urban construction and management, which is particularly important.

\section{Funding}

This study was supported by the 13th Five-Year Plan of Guangzhou Philosophy and Social Sciences in 2019 - Research on Guangzhou City Image Construction Based on the Perspective of Visual Rhetoric (Project Number: 2019GZGJ212).

\section{Disclosure statement}

The authors declare that there is no conflict of interest.

\section{References}

[1] Chen Y, 2009, Concept Analysis and Theoretical Framework. The Press, 2009(05): 103-104, 118.

[2] Han Y, Liu Z, Pei X, 2021, The Construction of Urban Myth with Public Participation - Takes the Image Construction of Changsha in Xiaohongshu UGC Short Video as an Example. New Media Research, 7(19): 10-19.

[3] Tan H, 2019, Cultural Imagination - Takes Macao City Image Construction as an Example. Young Reporter, 2019(35): 97-98. 
[4] Liu T, 2018, Imagery Theory: Image and Visual Speech Analysis. Journalism University, 2018(04): 19, 149.

[5] Tao S, 2008, Fish Culture, Southeast University Press, Nanjing.

[6] Marx KH, 1979, The 1844 Manuscript of Economic Philosophy, People's Press House, Beijing.

[7] Zhou X, (eds) 2013, The Visual Culture Reader, Nanjing University Press. 